\title{
Fiscal Policy and EMU: Challenges of The Early Years
}

\author{
Antonio Fatás and Ilian Mihov
}

\author{
INSEAD and CEPR
}

\section{INTRODUCTION}

This chapter studies the behavior of fiscal policy in the EMU countries after January 1999 and the challenges faced by national governments in the medium term. To provide a benchmark, we first look at the years that preceded the creation of the single currency area and then we ask whether the first two years after the launch of the euro represent a significant change in the overall trend towards fiscal discipline started with the Maastricht Treaty in 1991. In accordance with the basic prescriptions of this treaty, the current members of the European Economic and Monetary Union went through significant fiscal adjustments in preparation for the introduction of the new currency. In some cases, these adjustments took place in an unfavorable economic environment due to the low growth rates experienced during the first half of the 1990's. Overall, the process of fiscal adjustment complied with the Maastricht criteria and led to large reductions in budget deficits, especially in the years 1994-1997.

The introduction of the euro in January 1999 and the replacement of the Maastricht Treaty criteria by the rules of the Stability and Growth Pact have added new challenges in the conduct of fiscal policy under EMU. Although the Stability and Growth Pact should be conducive to an environment characterized by discipline in fiscal policy, there are still many unanswered questions on what is the best way to achieve and monitor that discipline and the effects that it will have on the real economy. One unresolved issue is how to determine whether increases in the budget deficit signify loose fiscal policy, which can be undone relatively quickly, as opposed to an indication of a need for a structural change in the conduct of fiscal policy. We argue below that there are important differences in the responsiveness of the deficit to key macroeconomic variables. One way to ensure that the $3 \%$ limit is not reached is to review and readjust the cyclical sensitivity of fiscal policy. Of course, the implications of such structural innovation for welfare must be discussed extensively before proceeding with their implementation.

In this chapter we provide a review of some of the questions raised by the behavior of fiscal policy in EMU. The first question that we want to tackle is whether EMU has made a difference. One hypothesis that we test is the idea that once EMU started, countries have reduced their efforts towards fiscal discipline, not only because the high growth rates of 1999 and 2000 that have kept budget balances under control, but also because the 'punishments' associated to the lack of fiscal discipline are not as visible and evident as in the years before EMU was launched. ${ }^{1}$ This question can only be answered by putting the last two years in the context of the large fiscal adjustment that has taken place in the previous years. Our strategy is to analyze policy stance in the first two years of the operation of the monetary union by comparing a measure of the cyclically adjusted primary balance to a measure of discretionary fiscal policy which is derived by allowing reactive fiscal policy to respond to the output gap, as well as to inflation and interest rates.

\footnotetext{
${ }^{1}$ Von Hagen, Hughes Hallett and Strauch (2001) provide evidence in support of this hypothesis.
} 
A second related question is the need for coordination of fiscal policy in a monetary union. As long as the divergence in fiscal policy is the result of differences in the business cycle, it would be difficult to argue that these differences would have any negative impact on the implementation of monetary policy. But when the differences in fiscal policy are the result of discretionary (or exogenous) changes in national fiscal policy, then the implementation of monetary policy and its interaction with fiscal policy might lead to tensions among different economic authorities. In order to assess the degree of coordination of discretionary fiscal policy we look at the cyclically adjusted budget balance as well as a constructed indicator of the fiscal stance for each of the countries and then calculate correlations of these indicators across different periods of time in our sample.

Finally, an important issue that has arisen is the medium-run target that countries should have in order to keep their budget deficits away from the 3\% limit. To answer this question one needs to produce estimates of the normal cyclical behavior of the budget deficit. These estimates can be, of course, different for different countries, which makes it difficult to adopt any general rule that can be applied to all members of EMU. There can also be asymmetries related to the cyclical position of the economy. While in recessions or slowdowns the budget deficit might be very responsive to the change in economic activity, this response can be much more moderate when growth is strong because of the tendency to spend some of the money collected through the cyclical increase in revenues.

The chapter is organized as follows. Section 2 provides some descriptive statistics on the behavior of fiscal policy in European countries before and after EMU. Section 3 calculates a fiscal policy stance index for all countries. This index is used to assess the degree of coordination of fiscal policy among all members of EMU. Section 4 focuses on the last two years and looks into the question of how different fiscal policy has been under EMU. Section 5 discusses mid-term challenges of fiscal policy. Section 6 concludes by looking at policy implications of our empirical results.

\section{FISCAL POLICY BEFORE AND AFTER EMU}

In the last ten years, European countries have experienced large budgetary adjustments as the result of the conditions set by the Maastricht treaty. The adjustment has been uneven during the decade. While in the first years (1991-1992) fiscal policy was either expansionary or neutral as indicated by different measures of the fiscal stance, starting in 1993 most countries moved to restrictions in fiscal policy that ensured a reduction in their budget deficits. Figure 1 shows the evolution of the budget deficit and the cyclically adjusted budget deficit in the period 1990-2000 for the EUR-11 countries. $^{2}$

\section{[Insert Figure 1 about here]}

The cyclically adjusted budget deficit in these countries moved from 5.9\% of GDP in 1991 to about $0.7 \%$ in 1999 . This process of adjustment was uneven, as most of the adjustment took place in the

\footnotetext{
${ }^{2}$ We use the terminology EUR-11 to refer to the 11 countries that joined EMU in January 1999. When we include Greece in the sample we talk about EUR-12. In some instances, when looking at EUR-11, we exclude Luxembourg from the sample because data are not available. In that case we talk about EUR-10. The source for the data on the cyclically adjusted fiscal variables is the European Commission (different sources).
} 
latter years, after 1995. The two most restrictive years were 1996 and 1997. The raw budget deficit shows a similar pattern except for an increase in the first years, which reflects the reduction in GDP growth rates and the associated decrease in the budget balance.

Regarding the composition of the adjustment, the reduction in budget deficits was achieved through a combination of a reduction in expenditures and an increase in tax revenues. Figure 2 shows the cyclically adjusted figures for government expenditures and taxes for the EUR-11 countries. In the case of expenditures, there is a reduction from $49.6 \%$ of GDP in 1991 to $48.3 \%$ in 1999 . During the same years, taxes were increased from $43.7 \%$ to $47.6 \%$.

\section{[Insert Figure 2 about here]}

In terms of timing, the adjustment has been uneven. While most of the fall in government expenditures took part in the second half of the 90's, the increase in taxes was more pronounced in the first 5 years. For example, during the first years (until 1993) government expenditures increased and peaked at a level of around $52 \%$ to come down to about $47 \%$ by the end of the decade. ${ }^{3}$ Taxes, on the other hand, increased rapidly in the years 1992-1997, reaching a level of $47.5 \%$ of GDP and have remained stable since then. ${ }^{4}$ One of the reasons for the uneven adjustment of government expenditures is the evolution of financial expenditures associated to the interest payments on the government debt. While interest payments increased from $4.8 \%$ to $5.5 \%$ in the period $1990-1993$, after 1995 the reduction in interest rates brought this burden down to $4.3 \%$ by 1999 . This means that about half of the reduction in government expenditures during the period 1995-1999 is due to a reduction in interest payments.

There are interesting differences across countries both in terms of the timing and the composition of the adjustment. Regarding the composition of the adjustment, there is a group of countries where most of the adjustment took place through continuous increases in taxes. The best example is probably Greece. In the period 1990-1999, cyclically adjusted taxes increased by about $11 \%$. Of course part of this increase might reflect improvements in tax collection, but clearly a large portion of the revenue jump comes from raising tax rates. On the other extreme, a country like Finland was able to reduce its budget deficit mainly through a large decrease in expenditures (about $12 \%$ in the period 1993-1997). ${ }^{5}$

Other countries followed more closely the behavior depicted for the aggregate in Figure 2 and relied on taxes for the first years and later switched to expenditures as the mean to achieve the desired reduction in budget deficits. ${ }^{6}$

When looking at cross-country differences, one interesting question is whether there has been any convergence in terms of fiscal policy. We will deal with this question in detail in the next section of the chapter but we want to take here a first look at some of the raw numbers. Figure 3 displays the standard deviation (for the EUR-11 countries) of the budget balance, taxes and government expenditures, all as a \% of GDP. ${ }^{7}$

\section{[Insert Figure 3 about here]}

\footnotetext{
${ }^{3}$ All the figures are adjusted for the effects of the business cycle.

${ }^{4}$ The most recent estimates for 2000 show a decrease of about 1 percentage point of GDP.

${ }^{5}$ There was also a decrease in taxes, mainly in the second half of the decade.

${ }^{6}$ Spain, Denmark or Belgium fit this pattern.

${ }^{7}$ Al figures are cyclically adjusted. Source: European Commission.
} 
In all three cases, the pattern is towards convergence, as the standard deviation declines throughout the 1990s. There should be no surprise in the convergence of budget deficits, given that it was one of the goals of the Maastricht Treaty, but what is more interesting is the convergence in the size of the government (measured by either taxes or government expenditures). While in 1991 the standard deviation of the taxes-to-GDP ratio in the EUR-11 countries was 6.03, it had gone down to 4.6 by 1999. There is even more convergence if we look at the EUR-12 countries were the equivalent figures are 6.6 and 4.5 or the EUR-15 countries, where it goes down from a peak of about 8.34 in 1993 to 6.3 by 1999 .

This evolution of the taxes-to-GDP ratio suggests that behind the trend towards similar budget deficits, the last ten years have also witnessed a trend towards a similar government size. This has been achieved largely through increases in taxes for the countries with the lowest tax burden but also through small decreases in some of the countries with the highest taxes-to-GDP ratio. Understanding this evolution is key to analyzing the prospects for further fiscal consolidation.

This observed convergence in taxes and expenditures is also useful to understand differences in the strategies of fiscal adjustment that we have observed in the last 10 years. As mentioned before, the fiscal adjustment of the last decade differed significantly in terms of its composition across countries. The composition of fiscal adjustments is known to have very strong implications in terms of its sustainability. As shown in Alesina and Perotti (1995), strategies to correct fiscal imbalances based on reductions in spending are much more likely to succeed than strategies based on increasing taxes. Von Hagen, Hughes Hallett and Strauch (2001) have provided a detailed study of the different strategies followed by European countries in their fiscal adjustment during these years, and constructed an index of sustainability. One element that is very important in the analysis of fiscal adjustment is the differences in initial conditions. As mentioned before, countries like Finland relied more heavily on reduction in government expenditures, while countries like Greece relied on increases in taxes. Is this related to the starting point of each of these countries? The answer is yes. Finland is, of course, one of the countries with a large government and Greece, on the other hand, has one of the smallest governments. Are these two countries isolated examples in terms of their strategic choices to reduce budget deficits? Figure 4 suggests that, on the contrary, this pattern can be generalized to all the countries in the EUR-12. Figure 4 shows the correlation between the adjustment in taxes during the last 10 years and the initial level of taxes to GDP. There is a very strong negative correlation between the two. Countries that started with small governments followed a strategy of raising taxes, while countries like Finland, relied on reducing the higher-than-average government expenditures. This strong correlation suggests that differences in strategies for fiscal consolidation are strongly related to overall trends towards more similar tax and expenditures shares of GDP across all countries in the sample. We will come back to the implications of this evolution later in the chapter.

\section{[Insert Figure 4 about here]}

Has EMU made a difference? An interesting question is whether with the introduction of the Euro there has been any change in the behavior of fiscal policy. Evidence from the first two years of the operation of the monetary union can provide some suggestive indication on the direction of the future evolution of fiscal policy under EMU. This evidence must be carefully combined with the data from the years preceding the monetary union given that they are strongly influenced by the conditions set in the Maastricht Treaty - with explicit and large punishments associated for those countries that did not meet the criteria. Although the Stability and Growth Pact shares some of the 
criteria of the Maastricht Treaty and establishes ways of punishing governments that do not abide by the 3\% limit on deficits, the mechanisms of enforcement of this limit is clearly weaker than what they were prior to 1999 .

Although the issue of the last two years will be a central part of our analysis in Section 4 of the chapter, here we provide some preliminary evidence of the effects of EMU on the overall trends of fiscal policy. Figures 1 and 2 above suggest that there has been some slowdown in the adjustment towards smaller deficits. This slowdown is much more evident in the last two years where the estimates show that the cyclically adjusted budget deficit has not changed significantly. Clearly, one of the reasons for this slowdown is the fact that the budget deficit is now below the $3 \%$ limit and, therefore, the need for further reductions is smaller than what it used to be. The behavior of taxes and expenditures are, on the other hand, more encouraging as the two years after the launch of the euro confirm the overall trend in reduction in government spending and, importantly, show also some movement towards reduction in taxes. Figure 3 provides evidence on what is driving the change in deficits, taxes and government expenditures. There is a continuation towards convergence in government size as measured by taxes or government expenditures. This convergence has resulted in decreases in taxes in countries that, once EMU started, felt less pressure to reduce their budget deficits and decided to reduce taxes to address the medium-term goal of reducing the tax burden. At the same time, some of the countries where taxes are the lowest continued with the adjustment of previous years, as they saw no need to reduce taxes. This has led to a mild increase in the dispersion of budget deficits. If this evolution were to continue we could start a process of increases in disparities in terms of budget deficits as long as the countries with larger governments are not able to keep up with the reduction in tax rates through a fall in government expenditures.

\section{[Insert Figure 5 about here]}

To put the last two years in the perspective of the cyclical conditions of the last decade, Figure 5 represents the change in the cyclically adjusted budget balance and the growth rate of GDP for the EUR-11 countries. There is no clear pattern that emerges from this graph. There seems to be a negative correlation between the size of the fiscal adjustment and the growth of GDP. ${ }^{8}$ One could think of this correlation as suggestive of the negative demand effects of decreases in budget deficits, but there are other events and changes in economic policy, such as the restrictive monetary policy of the early 90's that need to be brought into the picture to reach any definite conclusions. An alternative explanation is that periods of high growth are periods where there is a tendency for excess government spending, which leads to deficits that are larger than what the cyclical conditions would indicate. ${ }^{9}$ We leave this question open here and we will come back to it with some more concrete evidence in the next sections of the chapter.

\section{COORDINATION OF DISCRETIONARY FISCAL POLICY: AN ALTERNATIVE MEASURE OF DISCRETIONARY FISCAL POLICY}

\footnotetext{
${ }^{8}$ The correlation is about 0.51 .

${ }^{9}$ It is also possible that there is an asymmetric bias in the procedures used to cyclically adjust the budget balance.
} 
One of the key issues regarding fiscal policy in EMU is the degree of coordination of fiscal policy. From a theoretical point of view, the adoption of a single currency leaves national government with fiscal policy as the only tool to deal with asymmetric business cycles. An argument can be made to allow countries the required flexibility to deal with these asymmetric shocks. For this reason, the Stability and Growth Pact has been criticized as imposing too many restrictions on national fiscal policies (e.g. Eichengreen and Wyplosz (1998)). Along similar lines, Melitz (2000) has argued that discretionary policy should remain important and active under EMU. On the other hand, it is agreed that conducting a unified monetary policy requires a certain degree of coordination of fiscal policy (see Melitz (2000)). This need for coordination is one of the pillars of the Stability and Growth Pact.

When measuring the degree of coordination of fiscal policy a distinction needs to be made between the response of fiscal policy to cyclical conditions and changes in fiscal policy that are unrelated to the business cycle. Fiscal policy can react to national cyclical conditions through automatic stabilizers and through discretionary changes in response to economic conditions. Exogenous changes in fiscal policy can be the result of, for example, politically motivated changes in taxes or expenditures or changes associated to a process of fiscal consolidation. Distinguishing between all these types of fiscal policy changes, both conceptually and empirically, is very difficult. One possibility is to look at the budget deficit - either the deficit in the overall financial balance or in the primary balance. The most serious problem with this measure that makes it a poor indicator of discretionary fiscal policy is its endogeneity. The deficit captures both exogenous policy shifts as well as automatic reaction of fiscal variables to the state of the economy thus confounding policy effects and endogenous economic fluctuations. The alternative is to construct a cyclically adjusted budget deficit; a budget deficit adjusted for changes that are the result of the business cycle.

The construction of cyclically adjusted budget deficit can be carried out in a number of different ways. The endogenous nature of the budget balance can be handled, for example, by removing the reactive components, taxes and transfers, from the fiscal balance thus concentrating only on the autonomous components of spending. Admittedly this is a crude way of adjustment that might throw away important and interesting information. An alternative method is to construct a cyclically adjusted fiscal balance such as the one we have used in the previous section, a current practice at the European Commission, the IMF and the OECD. The adjustment is carried out by establishing a benchmark cyclical indicator (an output gap, for example) and relating the deficit to the state of the cycle relative to the benchmark. ${ }^{10}$ In the previous section we have made use of the cyclically adjusted measure of fiscal policy produced by the European Commission.

An important contribution to this literature is provided in Blanchard (1993). He argues that an indicator of discretionary fiscal policy must be relative in nature, i.e. fiscal policy stance can be judged as tight or loose only with a reference to a certain baseline year or reference value. The procedure outlined in his paper requires selecting a pre-specified benchmark and estimating elasticities of the different components of the budget with respect to a representative set of macroeconomic variables. The response of the budget deficit to current economic conditions is then constructed by using the estimated elasticities. The difference between this value and the actual budget deficit is a measure of discretionary fiscal policy. The original recommendation is to use unemployment, inflation, and interest rates in the construction of the induced changes in the budget balance. Indeed, a version of this indicator has been recently used in a paper by Alesina and Perotti

\footnotetext{
${ }^{10}$ See Alesina and Perotti (1995) for a discussion of these measures.
} 
(1995). In their study of fiscal consolidations in OECD countries they construct an indicator of fiscal policy by using the current rate of unemployment as the driving variable for transfers and taxes. Here we extend their work by taking a slightly agnostic but more general approach. We use gross domestic product (GDP) instead of unemployment and we include a measure of the price level and interest rates. We use GDP because it is a more comprehensive measure of the state of the economy. Inflation and interest rates are also included because the budget does depend on the current rate of inflation - possibly via delays in tax collection or indexation of some spending items - and on real interest rates via their direct effect on interest payments or on the decision to invest in public infrastructure.

We propose a methodology for adjusting the primary budget balance to obtain an indicator of discretionary fiscal policy. On the basis of this indicator we will study whether the first two years of the EMU have been accompanied by loose or tight fiscal policy and whether these first years have seen increasing dispersion in policy stance across member countries. Our methodology requires estimation of a regression of the primary deficit on various macroeconomic variables. The baseline regression contains logarithm of real GDP, logarithm of the implicit GDP deflator, ratio of primary deficit to output and the real short-term interest rate. This composition of the vector of explanatory variables must be regarded as the minimal set of macroeconomic variables necessary for the construction of an indicator of fiscal policy. The estimated equation is the following:

$$
Y_{t}=\sum_{i=1}^{k} a_{i} Y_{t-i}+\sum_{i=0}^{k} B_{i} X_{t-i}+v_{t}^{p}
$$

Where vector $X$ represents the set of macroeconomic variables necessary for estimating the induced changes in the budget balance. $Y$ is a measure of fiscal policy stance. The indicator of discretionary fiscal policy is the residual denoted by $\mathrm{v}_{\mathrm{t}}^{\mathrm{p}}$ - this indicator is orthogonal to the state of the economy captured by the current and lagged values of macroeconomic variables, which in our view corresponds to the notion of discretionary, as opposed to reactive, policy. ${ }^{11}$ To understand the correct meaning of this measure, it is useful to describe fiscal policy as consisting of three instruments: (a) automatic stabilizers like taxes and transfers - these are instruments that are structurally embedded in the budget and are difficult to change with a simple discretion of the executive branch; (b) reactive discretionary policy - these are usually spending items that are used to smooth business cycle fluctuations on ad hoc basis; their use can be detected as systematic correlation between output fluctuations and fiscal policy; and (c) non-reactive discretionary fiscal policy - these are programs which are implemented for reasons other than smoothing business cycle fluctuations. Our measure is using the definition in (c) to evaluate the degree of policy tightness. We use annual data and we find it reasonable to use only one lag of the macroeconomic variables and the policy measure in the econometric estimation. ${ }^{12}$

\footnotetext{
${ }^{11}$ In Fatás and Mihov (2001a) we offer an extensive discussion of the fiscal policy indicator. In the same paper we also show how the economy reacts to shifts in discretionary fiscal policy.

${ }^{12}$ In our previous work, Fatás and Mihov (2001a), we have checked the properties of our indicator by comparing it to a quarterly measure of fiscal policy proposed by Blanchard. We used US quarterly data for this exercise and we find that our indicator of fiscal policy stance is highly correlated with the measure based on Blanchard's (1993) suggestions and constructed by Alesina and Perotti (1995) - the correlation at quarterly frequency is 0.82 . This result is quite remarkable given the differences in specification and it provides some validation of our methodology. Moreover, we can identify from our analysis the major
} 
We turn now to our main data set that includes thirteen countries - USA, UK, Sweden and all EUR10 countries (all EUR-11 countries except for Luxembourg). The number of countries is restricted by data availability. For each country we have constructed an indicator of fiscal policy by running the regressions described by equation (1).

The question we want to address is whether the EMU countries have converged in terms of discretionary fiscal policy. We have seen in section 2 that there has been a convergence in terms of the cyclically adjusted budget balance. Here we propose an alternative measure of convergence, the cross-country standard deviation of the indicators of fiscal policy in any given year - if countries 'coordinate' fiscal policy we expect to observe small standard deviations. Figure 6 plots the evolution of the standard deviation over the last twenty years together with the standard deviation of the raw primary deficits of the EUR-10 countries. First, there is a clear downward trend in both measures of dispersion. Second, it is important to note, however, that the standard deviation of our indicator in 1999 attains a historical low of $0.48 \%$, which is half of the deviation in the beginning of the 1990 s and is at the most $60 \%$ of the deviation at any other point in the last twenty years. The evolution of the dispersion in the primary deficit is somewhat different - with the values in the last two years being comparable to other historical realizations but not much lower. The spike in 1997 in our measure is caused by Italy, whose government in order to qualify for the EMU ran a much tighter fiscal policy than what the macroeconomic conditions required. The fact that this episode causes a shift in the measure of policy stance validates the ability of our measure to capture shifts in discretionary policy that are unrelated to business cycle conditions.

\section{[Insert Figure 6 about here]}

Overall, Figure 6 confirms our previous results; there has been a remarkable convergence in terms of discretionary fiscal policy in the last 10 years.

A second interesting question is to see whether the member countries have used more or less extensively discretionary fiscal policy in the years preceding the start of the monetary union. Figure 7 shows the average volatility of discretionary fiscal policy in the EUR-10 countries. The volatility is calculated as the standard deviation of the policy indicator over a window of seven years - this measure will attain high values for countries that use often discretionary fiscal policy, and will be close to zero for governments who do rely mostly on automatic stabilizers or use discretionary policy only to react to the state of the economy. The graph plots the average of these volatility measures for EMU members excluding Luxembourg. By historical standards, the period 1993-1999 is the period with the smallest average volatility - countries in the monetary union have not used in this period discretionary fiscal policy as extensively as in previous periods. It is interesting to note that the heyday of discretionary interventions were the 1970 s - with average volatility of $1.42 \%$ twice as high as the volatility in the 1990s. The fiscal adjustments associated with the Maastricht treaty have been carried out (on average) in a more predictable manner - as responses to current economic conditions and not as abrupt changes in policy stance. Furthermore it is worth pointing out that this decline in volatility is not characteristic for the other countries in our sample - Sweden, UK and the US. ${ }^{13}$

changes in fiscal policy in the US: The Kennedy-Johnson tax cut in 1964, the Reagan tax cut of 1981, and the Gulf war, among others - hence our indicator of discretionary fiscal policy provides a reasonable match

with the historical record of US policy.

${ }^{13}$ The results for the non-EMU countries are available from the authors upon request. 


\section{[Insert Figure 7 about here]}

In summary, it is worth emphasizing that the conformity with the Maastricht criteria coincides with, possibly self-imposed, restrictions on using fiscal policy for purposes unrelated to the state of the economy. To the extent that some of the constraints are present in the Stability and Growth Pact, one can expect that the use of non-reactive discretionary policy will continue to be subdued. Furthermore, it is interesting to note that the EMU members have moved together in this direction as indicated by the decline in the disparity of fiscal policy stances across member states.

\section{HAS EMU MADE A DIFFERENCE: FISCAL POLICY IN 1999 AND 2000}

Despite the strong trends towards more discipline and more coordination of fiscal policy documented in the previous two sections, there are arguments that suggest that once countries have been allowed to enter EMU some of this discipline and coordination will disappear. In this section we take a look at the first two years of the operation of the monetary union and ask whether they look very different from the previous years. The answer will have a speculative flavor given the limited information we will be using. We are only talking about two years and some of the data for the year 2000 are not released or still subject to revisions.

Our approach is again to focus on discretionary changes in fiscal policy that are unrelated to the business cycle. In addition to considering the indicator of fiscal stance that we have constructed in Section 3, we will look also at conventional cyclically adjusted measures of fiscal policy. Our first step in order to assess the behavior of fiscal policy in the first two years of the EMU is to use the model of Section 3 and do a forecast of fiscal policy for the years 1999 and 2000. This forecast provides a measure of the fiscal policy that would be compatible with the current macroeconomic conditions. Of course, the forecast is based on a model that is estimated using data for several decades and one can argue that there have been changes in the structure of fiscal policy over this period. We still think that this exercise is useful because one can argue that there have not been significant changes to the response of fiscal policy to the business cycle, which is what is captured by the parameters of the model. Discretionary fiscal policy has certainly changed over the sample period, but as long as this is only the part of policy, which is unrelated to the state of the economy, then these shifts will be captured by the residuals of the model and thus recorded properly as shifts in fiscal policy. If there are changes in the responsiveness of the budget to economic activity, then our model will label these changes as discretionary shifts. It is clear however, that no procedure is immune to structural breaks - the key lesson is that in the interpretation one has to be cautious not to over-interpret the implications of different measures. Some analysts prefer to label the unexplained change in the budget deficit as a change in the budget sensitivity (see for example European Commission (2000), box 11). The change in the budget sensitivity is of course measured as a combination of various forecast errors. The truth, as usual, is somewhere between the two extremes - a portion of the forecast error can be attributed to discretionary policy and the rest might indeed be a change in the sensitivity of the budget. It is simply impossible to have a theoretically sound decomposition that will attribute the right portion to changes in responsiveness as opposed to discretionary policy. Therefore, we think about these forecasts of fiscal policy as rough but informative guide to what was expected in 1999 and 2000, given the macroeconomic conditions faced by these countries. 
Once the forecasts are produced, we then measure the difference between the predicted and the actual primary deficit. More precisely, we run regressions only with data up to 1998 and the estimated parameters are used to forecast the primary surplus in 1999 and 2000. To do this forecast, we use data on GDP and interest rates for 1999 and 2000, which ensures that the forecast errors are not associated to errors forecasting output. We represent these errors in Figure 8. The horizontal axis of Figure 8 captures the excess of the actual over predicted surplus in 1999, while the vertical axis plots this difference for 2000 .

\section{[Insert Figure 8 about here]}

As many as eight of the ten countries had larger than expected primary surpluses in 1999 (these are the countries to the right of the vertical axis). Since the results already take into account the state of the business cycle, the positive forecast error indicates tighter fiscal policy. On the basis of this result we can conclude that there is little evidence in favor of the 'fiscal adjustment fatigue' in 1999. Interestingly the situation changes in 2000: Italy, Germany, Spain and the Netherlands have now policy that is looser than what macroeconomic conditions imply. Only Ireland, Belgium and Portugal moved to tighter policy, while the other observations are below the 45-degree line, which indicates that these countries have loosened their policy stance. Still, even with this loosening in 2000, almost all EMU countries have been conducting fiscal policy close to neutral - with the excess surpluses or deficits not exceeding $0.5 \%$. The only exception is Portugal, where fiscal policy has been excessively tight. In fact, Portugal presents an interesting illustration of the informational content of our proposed measure of discretionary fiscal policy. Although the country has been criticized in 2000 for its low level of primary surplus (both unadjusted and after cyclical adjustment), our measure suggests that fiscal policy in Portugal is excessively tight. What is the correct interpretation of this seemingly serious disparity? By historical standards Portugal is expected to run a primary deficit under the combination of output growth, inflation and real interest rate in the country in 2000. Instead, possibly because of the pressure from the rest of the EMU members, it has attained a primary surplus. The most straightforward conclusion is that the budget elasticities in Portugal ought to be changed, i.e. the criticism that the primary surplus is low is not about the level of discretionary spending or tax collection, but about structural changes in fiscal policy. If this is the case, then this is an example of a desired change in the budget sensitivity. Alternatively, it is also possible, and plausible, that the nature of the budget in Portugal differs from the budgets in the other economies in its responsiveness to inflation and interest rates. This argument implies that there is no room for concern, since the low level of surplus does not necessary imply that once output growth slows down the country will get close to the $3 \%$ limit very fast - depending on the combination of inflation and interest rates this process of budget balance deterioration might be slower than in other countries. Although this interpretation is quite intriguing and points to the importance of looking beyond the output gap, it seems reasonable to insist on understanding the need for structural adjustment in the country.

In summary, considering all EUR-10 countries the developments in 1999 and 2000 indicate a movement in the direction of having neutral policy stance from the restrictive fiscal policy in the 1990s. This rather general finding is consistent across different measures of fiscal policy stance, as the movement towards neutral policy is also documented by Brunila and Martinez-Mongay (2001) who use the change in the cyclically adjusted primary balance as a measure of fiscal tightness.

The second test we propose is to look at a less structural measure of the fiscal policy stance, namely the one used in Section 2, the cyclically adjusted balance produced by the European Commission. 
We have seen before that in the last two years the cyclically adjusted balance has slowed down its trend towards smaller levels. Although this slowdown in the adjustment of the budget deficits is natural given that governments are all in compliance with the 3\% limit established by the Stability and Growth Pact, there are concerns that this is the result of procyclical fiscal policy. In fact, in Figure 5 we correlated changes in the cyclically adjusted balance and the growth rate of GDP and we showed that over the last ten years there was a negative correlation between the two series; i.e. there is a tendency for fiscal policy to be loose in periods of high growth. This correlation is also present in the last two years, although there is no sign (in Figure 5) that the change has been any different from what we have observed in previous years, in fact, it seems that fiscal policy is less loose than what it was in years with growth rates similar to what we have observed in 1999 and $2000 .^{14}$

Even if we accept the fact that fiscal policy has been somehow procyclical for the aggregate of EUR-11, can we learn anything by looking at differences across countries? Does the same pattern apply in the cross-section of countries? The answer is no. Figure 9 plots the change in the cyclically adjusted budget balance and the GDP growth rate in the year 2000 for the EUR-11 countries.

\section{[Insert Figure 9 about here]}

There is a remarkable positive correlation between the two variables. With the exception of Italy, all other countries lie in a perfect straight line. This correlation is also present in 1999 (although it is weaker), but it is not present in previous years. As an example, Figure 10 presents a similar plot for the year 1995, where no apparent correlation exists.

\section{[Insert Figure 10 about here]}

A correlation like the one of Figure 9 is remarkable and implies that those countries with faster growth rates have had more restrictive fiscal policy. In other words, the procyclical behavior of fiscal policy that we observe in the aggregate is not present when we look at differences in fiscal policy across countries. This result is encouraging because it is what is to be expected if fiscal policy becomes the tool to deal with national business cycles. Among the EUR-11, we see that countries with faster growth rates maintain more contractionary fiscal policy. It is difficult to extrapolate much from two years of data, but, certainly, in the cross-section of countries, we find no evidence of countries taking advantage of fast GDP growth rates to move towards looser fiscal policy.

\section{MEDIUM-TERM TARGETS FOR THE BUDGET BALANCE}

In the previous sections we have provided an evaluation of the behavior of fiscal policy in the first two years of the monetary union in a comparative perspective to fiscal policy in the years preceding the launch of the EMU. There is universal agreement in the literature that the 1990s have been dominated by a significant effort to achieve a level of the budget deficit and the government debt that were within the limits set by the Maastricht Treaty. Once that effort has been made and all countries in the European Union display deficits below the 3\% limit, the new question that arises is what the medium target level for the deficit should be. In the absence of an agreed optimal level of

\footnotetext{
${ }^{14}$ It is impossible to perform a formal test of this hypothesis given the limited number of observations. A formal test that distinguishes between the trend towards smaller deficits and the response of these deficits to the business cycle would require a much larger sample.
} 
the debt-to-GDP ratio, the decision on the medium target has been discussed within the context of the Stability and Growth Pact (SGP). Under the SGP, governments are still committed to keep the budget deficit below the $3 \%$ ceiling. The question on medium-run targets then becomes: what level of the budget deficit ensures that countries will never go beyond the 3\% ceiling? There are two issues that are relevant here. First, given the cyclical behavior of the budget balance, what level ensures that the deficit is below $3 \%$, even under the worst possible conditions? Second, given the predictions of large increases in ageing-related government expenditures (pensions, health), should this target be modified to take into account these additional expenses?

To answer the first question, an estimate of the cyclical elasticity of the budget balance is required. In a recent paper Artis and Buti (2000) review some of the estimates in the literature and provide additional calculations of the cyclical elasticities of fiscal variables. The first thing that is obvious from these estimates is that each country faces a different medium-term target because of the differences in the elasticity of the budget balance. Countries like Austria or France, because of their lower cyclical responsiveness of the budget balance, could ensure that the deficit never gets above $3 \%$ even if their medium-term target is a deficit of $1.3 \%$. On the other hand, Finland needs to maintain, as a medium-run target, a surplus of about $1.3 \%$, given that its business cycle is more volatile and that its budget surplus is more procyclical. ${ }^{15}$ These numbers should be taken with great care because of the following three considerations. First, there is no reason to believe that business cycle fluctuations will remain unaffected by EMU. In fact, the literature on the Endogenous Optimum Currency Areas has argued that business cycle will change, both in terms of crosscountry correlations and volatility of output. ${ }^{16}$ Second, in addition to the possibility that the properties business cycles might change, one has to recognize the fact that the unavailability of monetary policy for accommodating national shocks may lead to observing larger swings in fiscal policy as a smoothing economic policy tool for national business cycles. We have seen that there is some evidence in this direction from the data on cyclically adjusted balances for the year 2000. Third, the elasticity of the budget balance is strongly related to the size of governments. This phenomenon has been largely left unappreciated. Van der Noord (2000) presents empirical evidence for the OECD economies, while in Fatás and Mihov (2001b) confirm the finding and show that the result also holds for US states. This empirical regularity implies that if the trend towards a similar government size continues - a trend documented in this chapter - then we should expect to see also a convergence towards a similar cyclicality of budget balances. Under this scenario differences in fiscal policy across countries will reflect either idiosyncratic output fluctuations or idiosyncratic changes in discretionary policy, but not differences in budget sensitivity.

There is one question that has not been dealt with in this debate, the implications of these targets on the composition of fiscal policy. Are there any consequences on the levels of taxes and government expenditures that can make the medium-term targets more successful achieving the goal of not having a deficit above $3 \%$ ? The answer to this question is a complex one and there are many considerations to be made, from the differences in elasticities of different components of fiscal policy to the sustainability of different fiscal policy adjustments depending on how they are achieved. Without entering into some of these complex debates, one thing that our previous analysis made evident is that countries need to take into account their medium-term targets in terms of taxes and government expenditures to keep them consistent with their targets for budget

\footnotetext{
${ }^{15}$ All the above estimates are taken from Table 3 of Artis and Buti (2000).

${ }^{16}$ See Frankel and Rose (1997), Bayoumi and Eichengreen (1997) and Fatás (1997).
} 
balances. For example, countries with smaller governments have achieved a reduction of the budget deficit largely through an increase in taxes. These increases cannot continue in the future, which will require more focus on the control of government expenditures, if there was any trend towards higher deficits. Similarly, for countries with larger governments, there needs to be much more pressure on reducing or, at least, keeping under control government expenditures given that a medium-term goal of reducing taxes needs to be made compatible with the target of a sustainable budget balance.

Finally, when one looks at the coming decades, the budget implications of the demographic changes towards an older population need to be taken into consideration. As suggested by previous authors, the fact that the demographic transition might result in improved budget balances in the short-term but deteriorating balances in the long-term, makes it even more necessary, to foresee its implications on national budgets and build the necessary room to accommodate these changes. Estimates on the increase in government spending associated to ageing vary dramatically depending on assumptions on productivity growth, functioning of the labor market or the fate of ongoing reforms on social security. The forecasted increase in government expenditures for the next three decades as a result of this demographic transition is around 5 percentage points for most of the European countries. Given the $3 \%$ ceiling on budget deficits, such a large increase in expenditures needs to be taken into account when setting medium-term plans for fiscal policy. ${ }^{17}$

How should targets be changed as a result of the predicted increase in government expenditures? Should countries stick to the $3 \%$ ceiling on budget deficits? While there are benefits to stick to such a rule to ensure that the adjustment is not simply postponed, from an economic point of view the changes in fiscal policy that are required to deal with a demographic transition like this one are far more cumbersome than what a 3\% rule implies. The main issues in this debate are about intergenerational fairness and who is going to pay for the increased expenditures in future decades. To answer such a complex question models of intergenerational transfers that are specific to each country need to be studied. These models need to consider, among many other things, the current level of government debt, a variable that was present in the Maastricht Treaty but was removed from the Stability and Growth Pact. Although it is true that by controlling the budget deficit one controls the increase in government debt. It is also true that the optimal response of budget deficits to a demographic transition that implies both temporary and permanent changes in government expenditures cannot be the same for a country with practically no government debt and for a country with a stock of debt around $100 \%$ of GDP. ${ }^{18}$

\section{CONCLUSIONS AND POLICY IMPLICATIONS}

In the previous sections we have analyzed the behavior of fiscal policy under EMU and during the years that preceded the launch of the single currency. What implications can be derived for the future conduct of fiscal policy? Clearly, any policy conclusions must be interpreted with caution, because they are based on information only in the first two years of the operation of the union and

\footnotetext{
${ }^{17}$ Regardless of the ceiling on budget deficits, any sensible plan for fiscal policy over the next three decades needs to take into account the exceptional circumstance caused by the ageing of the population of European countries.

${ }^{18}$ Artis and Buti (2000) also highlight the importance of the current level of government debt because of the different savings that can be achieved through reductions in interest rate payments.
} 
thus can only provide us with limited information on the changes in behavior that EMU has triggered. The design of fiscal policy under EMU is going to be a learning process as countries go through different circumstances introduced by a single monetary policy and its interactions with 12 national governments that decide on taxes and expenditures.

$\checkmark$ In the last decades, we have seen a significant process of convergence in terms of fiscal policy. This convergence goes beyond the well-documented convergence in budget deficits, started as a result of the fiscal policy criteria in the Maastricht Treaty. Our analysis of the cyclically-adjusted budget balance as well as a constructed measures of discretionary fiscal policy also indicates that there is today much more symmetry in terms of fiscal policy than a decade ago. This convergence has come with a reduction in the use of discretionary policy over the last 3 decades.

$\checkmark$ Although the convergence process has nominally concluded in 1999, there is no evidence that this has induced a step back in the direction of more divergence once countries have been allowed to be part of EMU and are therefore less threatened by the possibility of excessive deficits. In other words, there is not much evidence of 'fiscal fatigue' in the last two years.

$\checkmark$ The convergence in budget deficits and the fiscal policy stance has been accompanied by a convergence in average tax rates. This convergence has been probably faster than the process of real convergence (e.g. convergence in real GDP per capita). These trends can justify the different strategies pursued by different countries in their adjustment towards lower deficits. Countries such as Finland have relied heavily on a reduction in government expenditures because they started with a large government size. On the other hand, countries like Greece, that had the smallest government at the beginning of the decade, has relied on large tax increases to reduce its budget deficit.

$\checkmark$ The previous trend towards similar government size has also been accompanied recently by a trend towards smaller governments. The taxes-to-GDP ratio in the EU, while it increased substantially in the period 1990-95, has remained stable in the last years and is expected to fall in the coming years. This trend poses some challenges to countries that have high tax burdens and have relied somehow on tax increases to control the budget deficit. As these countries start decreasing their tax rates, they will face pressure to reduce their expenditures if they do not want their budget deficits to increase. As it is well known from the literature on fiscal consolidations, success depends on the ability to control government expenditures. If any, this is the only possible sign of fiscal fatigue that we see in the data, the fact that some countries have launched ambitious plans to cut taxes and these plans can only be sustainable if government expenditures are kept under control. Although we do not see any alarming signs in the behavior of budget deficits in 1999 and 2000, this is one of the issues that will need more attention and monitoring in the coming years.

$\checkmark$ In the last two years, has the behavior of fiscal policy been consistent with the business cycle position of European economies? Overall, we find that fiscal policy has been in accordance with the phase of the business cycle and, if any, has been stricter than what it has been in the past, given the current conditions. We reach these conclusion using two different methods. First, in our econometric specification, we forecast budget balances for 2000 using information on GDP growth rates and interest rates for 2000 and, for most countries, the predictions are very close to the balances observed. Second, we look at the 
behavior of cyclically adjusted budget deficits over the business cycle to see if there is any bias or asymmetries in different phases of the business cycle. In the last decade, there is a negative correlation between these two variables, which suggests that periods of high growth tend to be periods where fiscal policy becomes looser. ${ }^{19}$ In the last two years, this bias has been reduced and, more importantly, we observe in the year 2000 a very strong and positive correlation between cyclically adjusted budget balances and the growth rate of GDP across EUR-11 countries. Although one cannot read much out of the observations in one year, this evidence could be interpreted as a sign that fiscal policy has become the only tool to stabilize national business cycles and is more related to GDP growth rates than what it used to be in the past.

$\checkmark$ We have also discussed briefly the issue on how to set targets for the budget balance in order to ensure that countries are away from the $3 \%$ ceiling on budget deficits. The existing evidence suggests that, giving the cyclical elasticities of budget deficits, a 'close-to-balance or small surplus' fits most of the EUR-11 countries and can accommodate not only the type of downturns that we have seen in the last decades but also the 'erratic' component of the budget. Our only qualification regarding these recommendations is the possibility that business cycles, as well as the cyclicality of the budget, changes with EMU. While these changes are not expected to be dramatic, there are reasons to believe that the cyclicality of taxes will be reduced as governments reduce their size. Assuming that this does not get compensated with more responsive fiscal policy, as a result of the lack of monetary policy, this could increase the margin for error in the design of fiscal policy for the coming years.

$\checkmark$ A final issue that is relevant when looking beyond the next decade is the impact that an ageing population will have on government expenditures. Estimates of this impact for most European countries suggest that ageing will increase government expenditures by about 5\% of GDP. This increase is large and there should be no question about whether an adjustment is required. The relevant question is what type of adjustment should take place. Here, we argue that the answer cannot simply be based on the $3 \%$ budget deficit rule (i.e. follow a policy that never takes the budget deficit beyond 3\%). To be able to answer this question one needs to address issues of intergenerational fairness that go well beyond the reasons behind the 3\% limit on deficits. These issues need to be studied in the context of each of the European countries and need to take many of the idiosyncrasies of these countries into account (starting with the current level of debt, a variable that was dropped from the Stability and Growth Pact). While there is no reason to believe that the conclusion of this analysis will lead to fiscal policy plans that will temporarily take the budget deficit above the $3 \%$ limit, there needs to be enough flexibility when setting the policies to avoid falling into the trap of using one rule that was not intended to deal with the exceptional circumstances that ageing will bring to fiscal policy. ${ }^{20}$

\footnotetext{
${ }^{19}$ We are aware of the difficulty in making such a statement given the serious endogeneity problems when looking at fiscal policy and the business cycle.

${ }^{20}$ Other countries are facing similar issues. For example, the recent debates on fiscal policy in the US are about intergenerational transfers associated to the expected fluctuations in the social security balance over the coming years.
} 


\section{REFERENCES}

Alesina, Alberto and Roberto Perotti (1995). "Fiscal Adjustment". Economic Policy, 21.

Artis, Michael J. and Marco Buti (2000). "'Close to Balance or in Surplus': A Policy-maker's Guide to the Implementation of the Stability and Growth Pact". CEPR Discussion Paper Series, 2515.

Bayoumi, Tamim and Barry Eichengreen (1997), "Ever Closer to Heaven? An Optimum-CurrencyArea Index for European Countries." European Economic Review.

Blanchard, Olivier (1993). "Suggestions for a New Set of Fiscal Indicators", in H.A.A. Verbon and F.A.A.M. van Winden (editors), The New Political Economy of Government Debt, Elsevier Science Publishers.

Brunila, A. and C. Martinez-Mongay (2001) "The Challenges for Fiscal Policy in the Early Years of EMU," chapter in this volume.

Eichengreen, Barry and Charles Wyplosz (1998). "The Stability Pact: More than a Minor Nuisance?" Economic Policy, 26.

European Commission (2000). "Public Finances in EMU - 200" European Economy, 3-2000.

European Commission (2001). "Report on the Implementation of the 2000 Broad Economic Policy Guidelines", ECFIN/176/01.

Fatás, Antonio (1997). "EMU: Countries or Regions? Lessons from the EMS Experience." European Economic Review.

Fatás, Antonio and Ilian Mihov (2001a). "Fiscal Policy and Business Cycles: An Empirical Investigation" forthcoming in Moneday y Crédito.

Fatás, Antonio and Ilian Mihov (2001b). "Government Size and Automatic Stabilizers", forthcoming in Journal of International Economics.

Frankel, Jeffrey and Andrew K.Rose (1997) The Endogeneity of the Optimum Currency Area Criteria. European Economic Review.

Giavazzi, Francesco and Marco Pagano (1990). "Can Severe Fiscal Adjustments Be Expansionary?” NBER Macroeconomics Annual, MIT Press.

van der Nord, Paul (2000). "The Size and Role of Automatic Fiscal Stabilizers in the 1990s and Beyond”. OECD Working Paper, ECO/WKP 2000 (3).

von Hagen, Jurgen, Andrew Hughes Hallett and Rolf Strauch (2001), "Budgetary Consolidation in EMU", Economic Papers No. 148. ECFIN.

\section{APPENDIX}

DATA SOURCES. Cyclically adjusted figures for taxes, government expenditures and budget deficits are from the European Commission (different sources). Data to calculate the indicators of discretionary fiscal policy comes from the OECD economic outlook. 
Figure 1. Fiscal Adjustment in the 90's. EUR-11

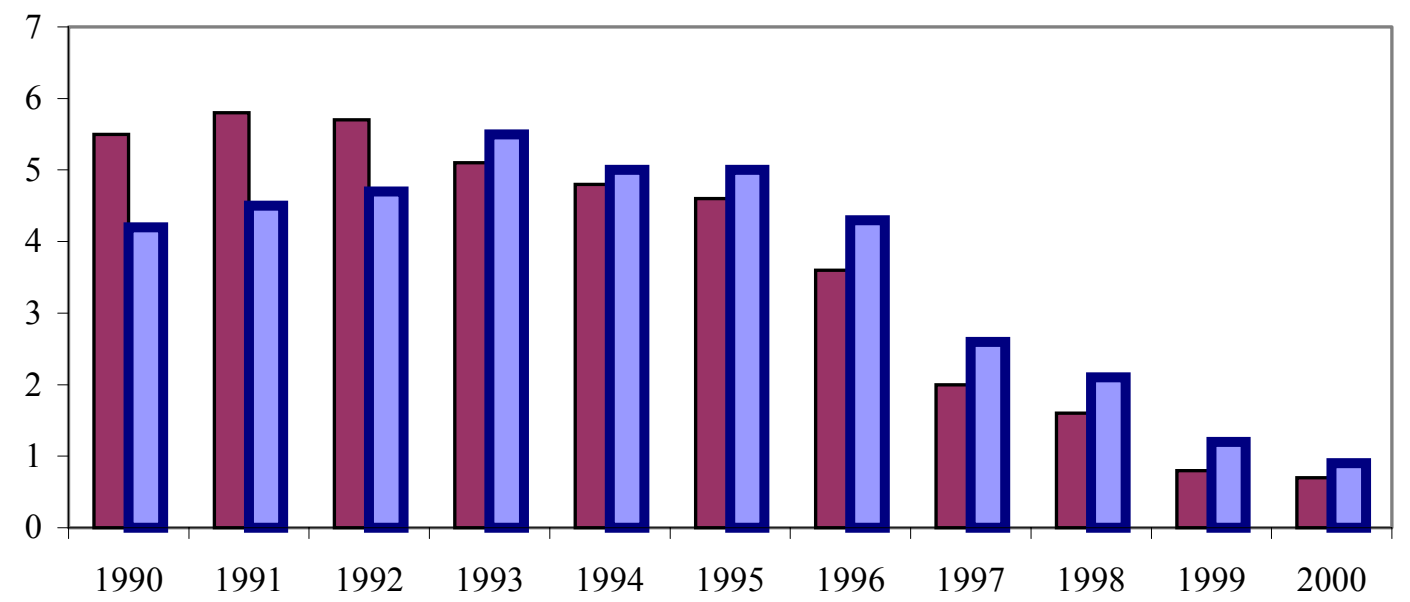

$\square$ Cyclically Adjusted Budget Deficit $\square$ Budget Deficit 
Figure 2. Fiscal Adjustment in the 90's. Cyclically Adjusted Fiscal Variables. EUR-11

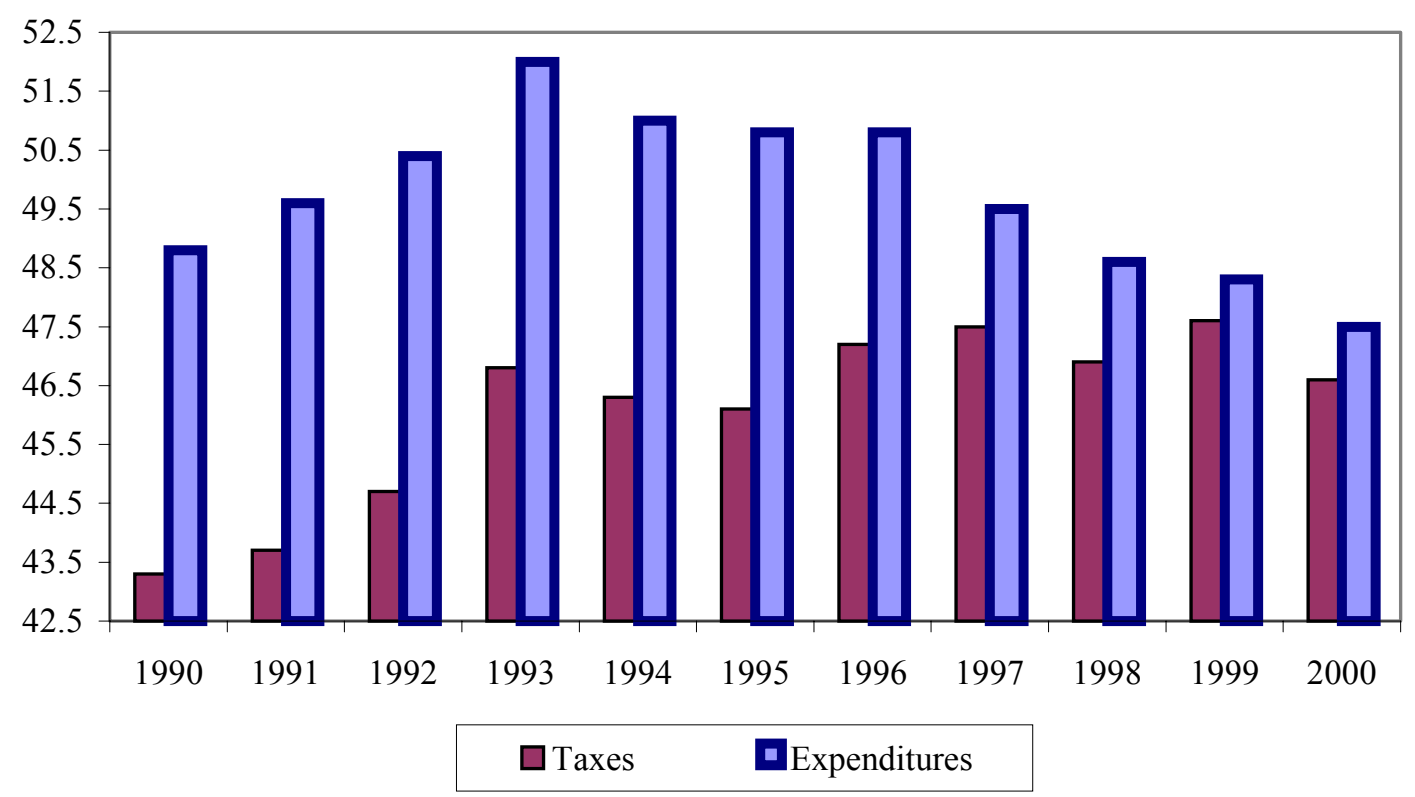


Figure 3. Cross-country Standard Deviation of Cyclically Adjusted Fiscal Variables. EUR-11

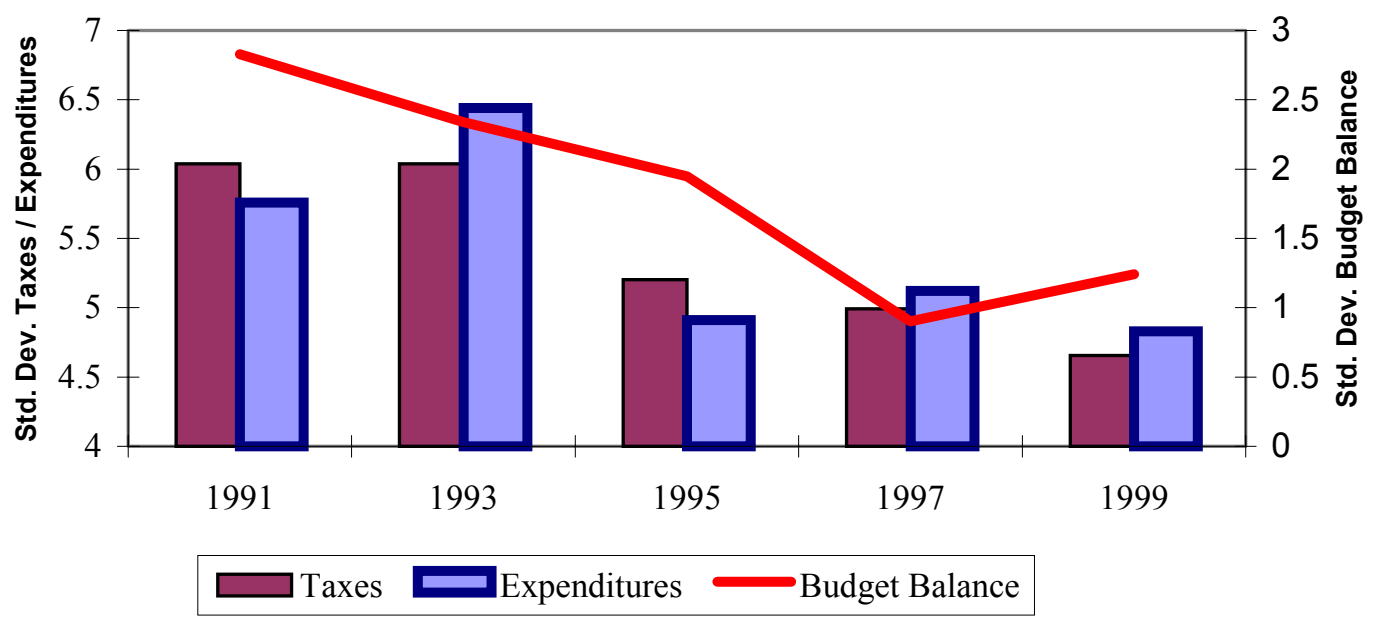


Figure 4. Fiscal Adjustment and Initial Conditions

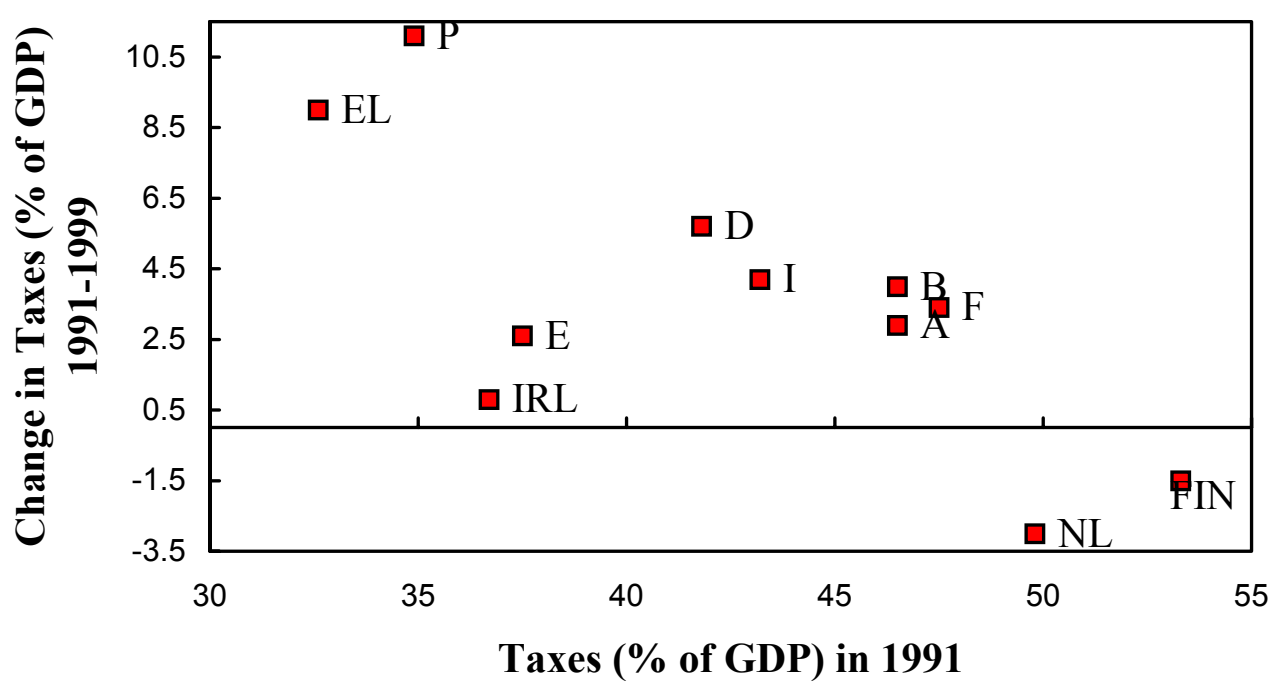


Figure 5. Fiscal Adjustment and the Business Cycle

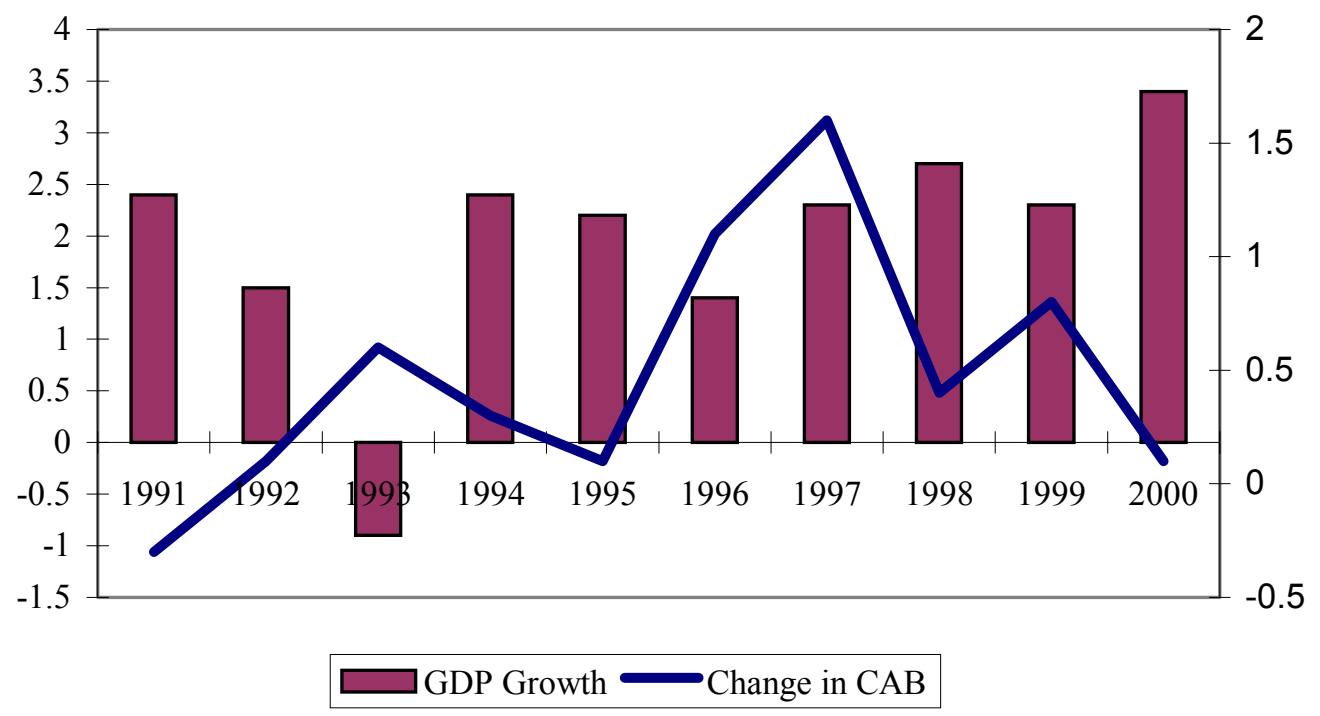


Figure 6. Coordination of Fiscal Policy. Standard Deviation of Indicators of Fiscal Policy. EUR-10

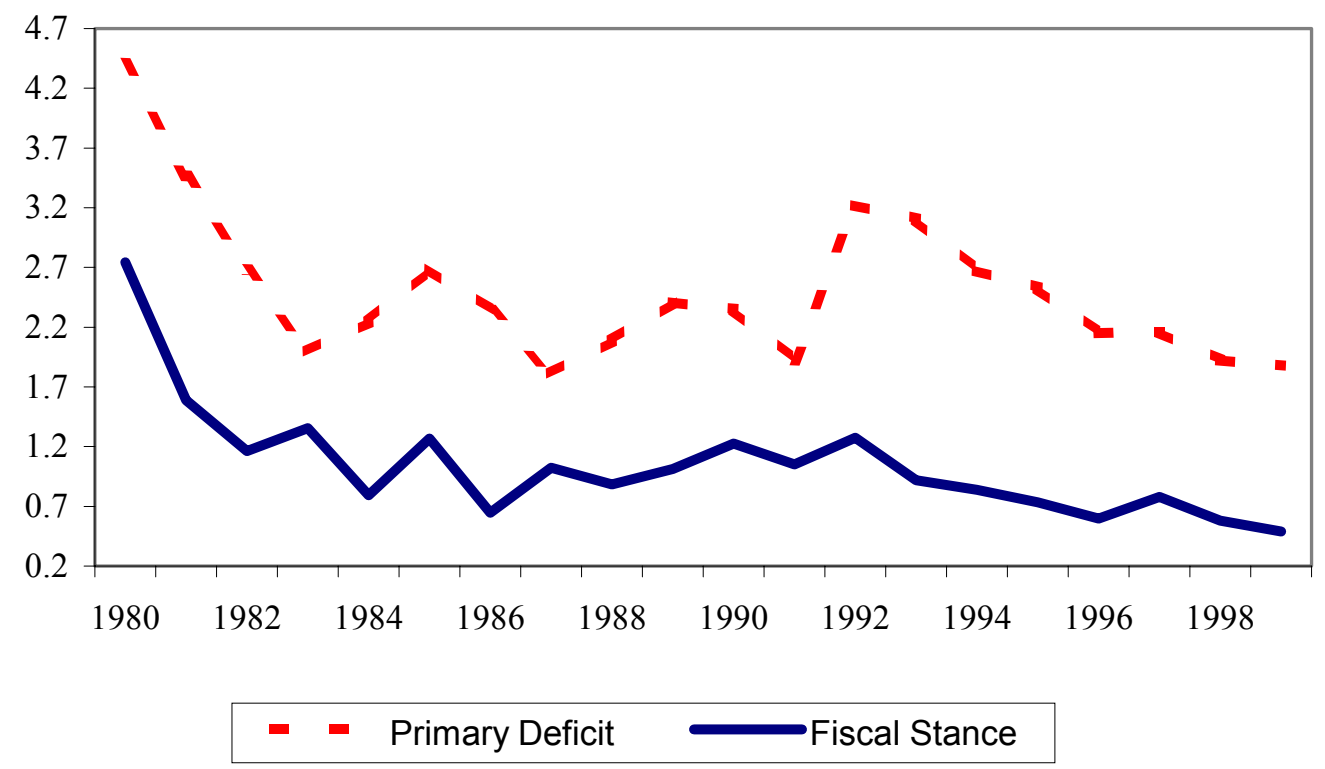


Figure 7. Volatility of Fiscal Policy. EUR-10

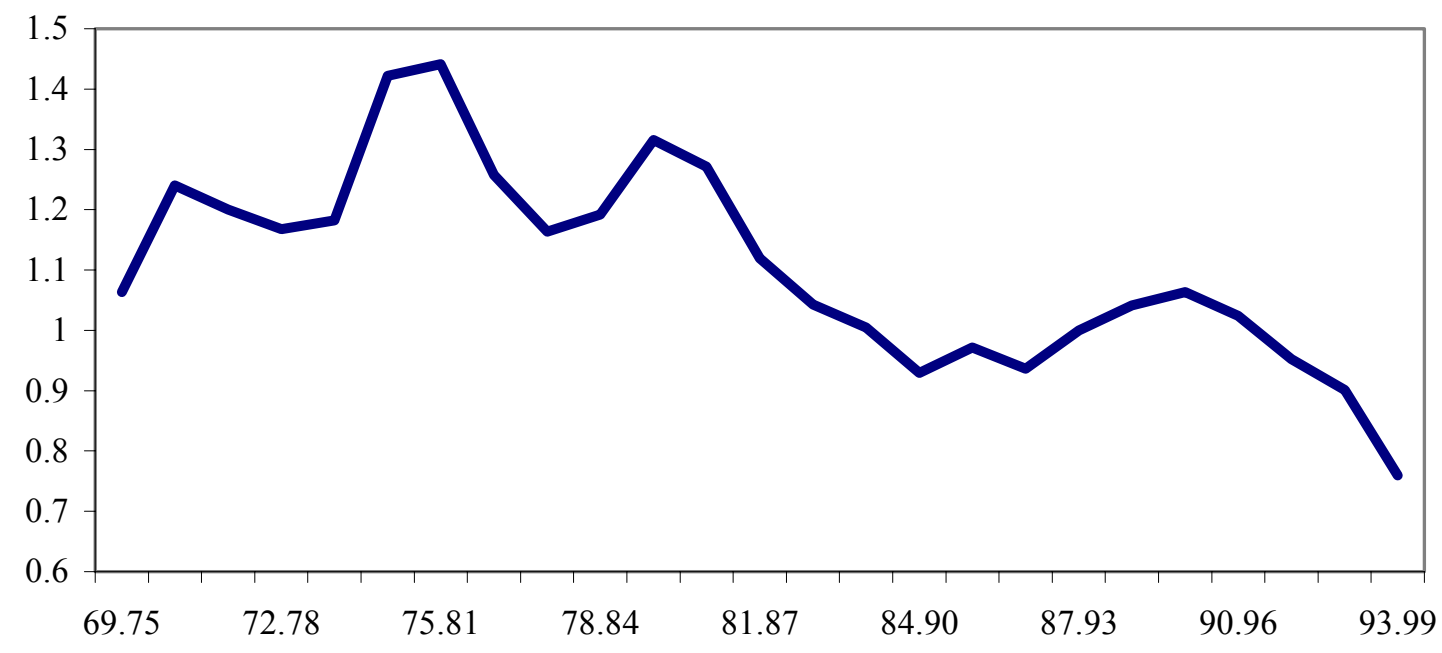


Figure 8. Fiscal Policy Forecast Error. 1999/2000

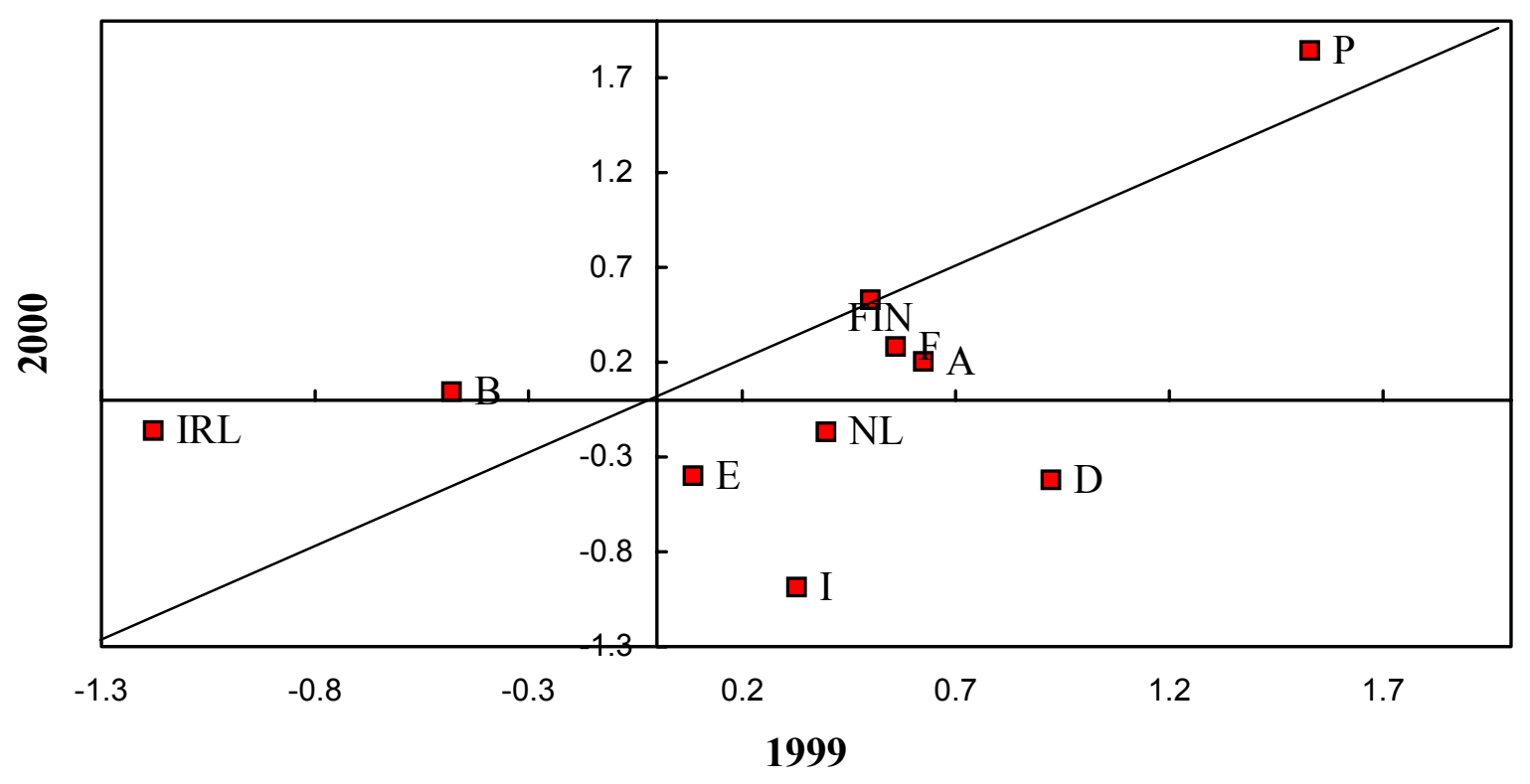


Figure 9. Fiscal Policy Stance and Growth. 2000

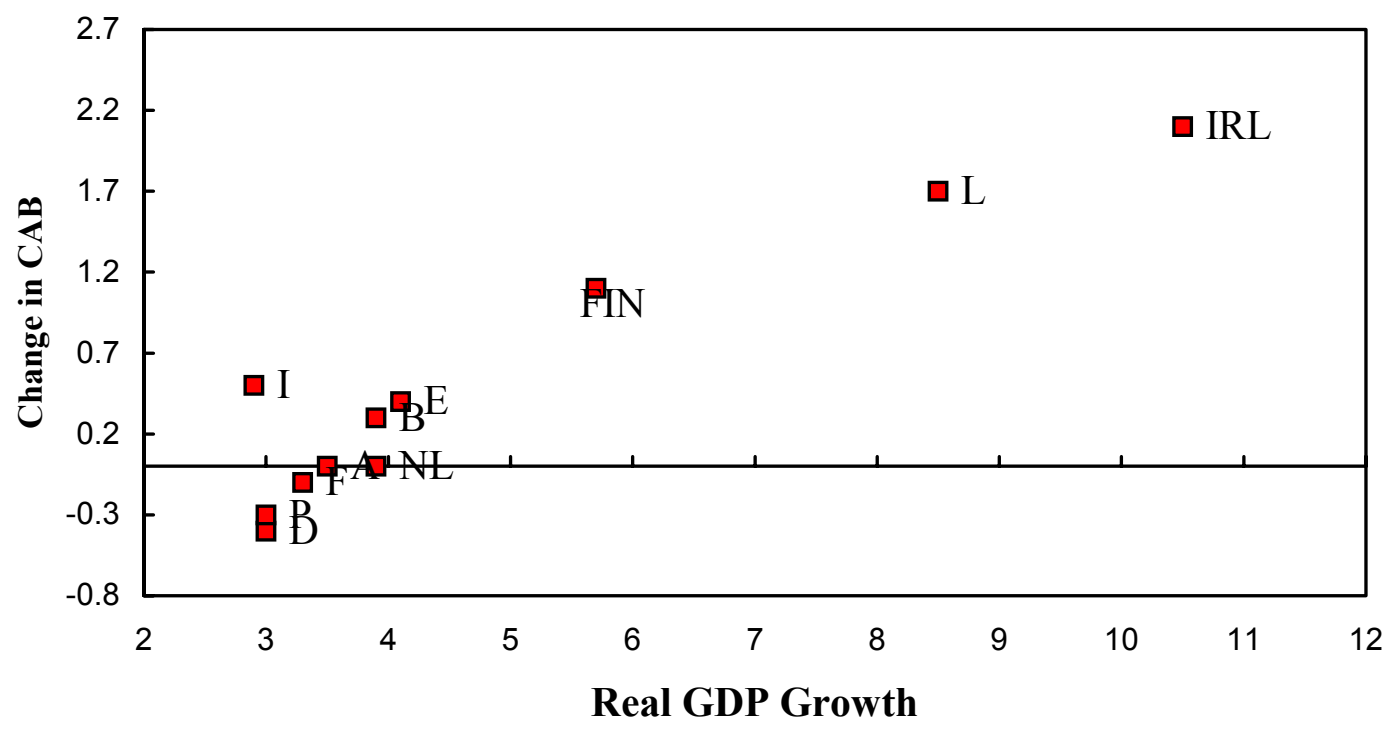


Figure 10. Fiscal Policy Stance and Growth. 1995

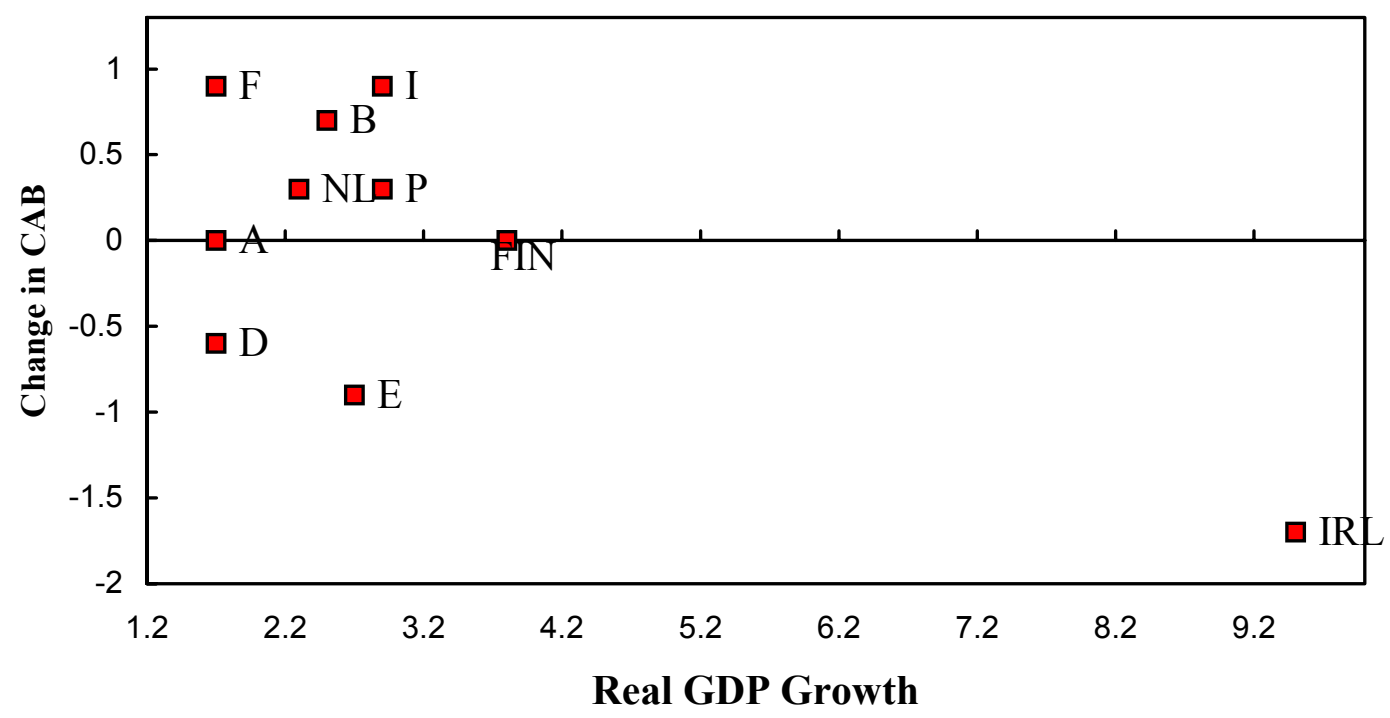

